\title{
Tax competition, trade liberalization, and imperfect labour markets
}

\author{
By Peter Egger* and Tobias Seidel $\uparrow$
}

${ }^{*}$ Department of Management, Technology, and Economics, ETH Zurich; CEPR; CESifo; and GEP, University of Nottingham

$\uparrow$ CESifo and Department of Management, Technology, and Economics, ETH Zurich, WEH E4, Weinbergstrasse 35, 8092 Zurich, Switzerland; e-mail: seidel@kof.ethz.ch

\begin{abstract}
In this paper, we study the link between trade liberalization and imperfect labour markets for tax competition. We show that rigid labour markets increase the mobility of the tax base as compared to perfect labour markets translating into lower Nash tax rates. Lower trade barriers exhibit a similar effect. It turns out that the imperfect labour market and the trade liberalization channels are interdependent.
\end{abstract}

JEL classifications: F12, F15, F21, H87, R12.

\section{Introduction}

In spite of dramatic cuts in tariffs and technological progress with regard to transport infrastructure, costs of cross-border goods trade are still surprisingly high (see Anderson and van Wincoop, 2004). Trade costs may to some extent shield markets from foreign competitors so that it becomes attractive for firms to locate in the larger market where the majority of customers resides. Obviously, this has crucial implications for tax competition as governments in large markets can use this location advantage to attract foreign firms and charge higher tax rates.

A second important fact that governments have to take into account when choosing the optimal capital income tax rate is imperfect labour markets. Specifically in continental Europe, countries have witnessed substantial and persistent levels of unemployment. How should governments ideally adjust their tax rate on mobile capital to declining trade costs that deepen the integration of markets if labour markets do not work perfectly? This question is at the heart of this paper. We provide a framework that helps understand better the interplay between labour market frictions and trade liberalization for tax competition. 
Our model considers two countries that produce a homogeneous traditional and a composite industrial good with the inputs capital and labour. While labour is assumed to be mobile only between domestic sectors, capital can also cross international borders. As trade in industrial varieties is subject to trade costs, our model features the well-known home market effect. We follow Akerlof and Yellen (1990) and in particular Kreickemeier and Nelson (2006) and Grossman and Helpman (2008) in modeling labour market imperfection by means of fair wage preferences of individuals. ${ }^{1}$ This introduces an elegant link between relative factor prices and unemployment which is central to a large set of labour market rigidities (e.g., minimum wages, collective bargaining). The advantage of the Akerlof-Yellen approach lies in its single (fair wage) parameter that describes the intensity of the labour market imperfection. Moreover, relative factor prices and unemployment can be endogenously determined in general equilibrium. Finally, our model allows for differences in market size and the degree of labour market rigidity between countries.

The paper is related to at least three strands of literature. First, there are a number of papers that study the tax competition game in a framework with imperfect product markets and trade costs. A general feature of these models is that firms find it attractive to agglomerate in one location for sufficiently low impediments to trade. In that case, governments can tax the agglomeration rent without any distortions. This point has been made by Ludema and Wooton (2000), Kind et al. (2000) and-for partial agglomeration-by Borck and Pflüger (2006). Baldwin and Krugman (2004) draw similar conclusions and point out in addition that tax coordination will be harmful to at least one country. Ottaviano and van Ypersele (2005) contribute a full-fledged welfare analysis and show that tax competition might enhance efficiency by improving the allocation of firms. A second strand looks at tax competition with rigid labour markets in a setting without trade costs and perfect competition on the product market (see, e.g. Fuest and Huber, 1999). Finally, the 'bidding for firms' literature considers rigid labour markets as well (see, e.g. Barros and Cabral, 2000, Bjorvatn and Eckel, 2006, and Haufler and Mittermaier, 2011). The central feature of this literature is that governments try to attract a single firm. None of these papers, however, looks at the interrelation between trade liberalization and rigid labour markets for tax competition.

Against this background, our paper delivers two main contributions to the existing literature. First, we show that a symmetric increase in the labour market rigidity of two identical countries renders tax competition more severe and reduces equilibrium tax rates for all levels of trade costs. A similar effect materializes if trade barriers are reduced. Furthermore, the impact of rigid labour markets and that of trade liberalization on equilibrium tax rates are interdependent. Higher trade

\footnotetext{
${ }^{1}$ See Bewley (2005), Gächter and Fehr (2002), Howitt (2002), Luttmer (2005), and Milkovich and Newman (2005) for evidence on this mechanism.
} 
impediments lead to a stronger responsiveness of equilibrium capital income tax rates with respect to changes in labour market rigidities than lower ones.

Second, we study the role of differences in market size and labour market rigidity for tax competition in this setup. Our results suggest that the advantage of having the larger market relative to the disadvantage of possessing a more constrained labour market crucially depends on the level of trade costs. While low trade barriers stress the market size advantage, higher trade barriers amplify the relative importance of labour market frictions. This is reflected in the optimal Nash tax rate.

The remainder of the paper is organized as follows. Next, we present the model with taxes on capital income and labour market imperfection. Section 3 provides analytical results in the short run where capital mobility is ruled out and only trade in goods is possible. In Section 4, we analyse the impact of fair wage preferences on the equilibrium share of firms and on Nash tax rates. Section 5 concludes.

\section{The model}

Consider a world with two countries $i=h, f$, populated by two types of individuals. Workers supply one efficiency unit of labour, $L_{i}$, and capital owners offer one unit of capital, $K_{i}$. We assume that both workers and capital owners are immobile internationally. However, capital itself can be moved across borders and employed in either country. These production factors are used to produce two tradable goods, $X$ and $Y$. One sector operates under perfect competition and produces a homogeneous traditional good $(Y)$ while the other sector is characterized by monopolistic competition. Manufacturing firms produce industrial varieties $v$ which are aggregated to the composite commodity $X$. We assume that trade of $Y$ is free while trade in $X$ is subject to iceberg-type trade costs $\tau>1$. This implies that $\tau$ units have to be shipped for one unit to arrive at its final destination abroad. Furthermore, we follow Martin and Rogers (1995) in assuming that capital owners globally diversify their capital to earn the average return. Since foreign income is always repatriated, this fixes market size despite capital mobility. These simplifications in particular allow a closed-form solution of the endogenous allocation of industry. However, the assumption of an imperfect labour market introduces complexity that constrains us to numerical solutions with respect to Nash tax rates in the long run. The building blocks of the model are laid out in more detail in the sequel of this section.

\subsection{Preferences}

Individual utility in country $i$ is given by

$$
O_{i}=\mu \ln \left(C_{X i}\right)+C_{Y i}+\ln \left(G_{i}\right), \quad \mu>0,
$$

where $C_{X i}=\left(\int_{v \in V} \tilde{x}_{i}(v)^{(\sigma-1) / \sigma} d v\right)^{\sigma /(\sigma-1)}$ is a CES-aggregator capturing demand for industrial goods and $C_{Y i}$ denotes aggregate demand for the traditional good. The parameter $\sigma$ represents the constant elasticity of substitution between any two 
industrial varieties, $\mu$ captures the preference for industrial relative to traditional goods, $\tilde{x}_{i}(v)$ is demand for variety $v$ in country $i$ and $V$ reflects the mass of industrial products in both countries. In addition, households derive utility from consuming a public good $G_{i}$. The private budget constraint is given by

$$
E_{i}=\int_{v \in V} \widetilde{p}_{i}(v) \tilde{x}_{i}(v) d v+P_{Y i} C_{Y i}
$$

where $\widetilde{p}_{i}(v)$ and $P_{Y i}$ describe consumer prices of a manufactured variety and the traditional good, respectively. Note that $E_{i}$ captures income net of taxes. It is convenient to choose $Y$ as numéraire so that its price equals one. Defining $P_{X i} \equiv \int_{v \in V} \widetilde{p}_{i}(v)^{1-\sigma} d v$ as the CES-price index, maximizing (1) subject to (2) yields

$$
C_{X i}=\frac{\mu}{P_{X i}}, \quad C_{Y i}=E_{i}-\mu, \quad \tilde{x}_{i}(v)=\mu \widetilde{p}_{i}(v)^{-\sigma} / P_{X i}
$$

\subsection{Technology}

There is perfect competition in the traditional sector and we assume that one efficiency unit of labour is necessary to produce a single unit of the traditional good, so that $L_{Y i}=Y_{i}$. As trade in $Y$ is not subject to any barriers and we focus on scenarios where both regions always produce $Y$, the price of the traditional good is unity everywhere. Together with the assumption that labour is mobile between domestic sectors (but not internationally), we get $w_{i}=1$.

In the industrial sector, both capital $K$ and labour $L$ are necessary for production. We use the assumption of Flam and Helpman (1987) that one unit of capital is required for firm setup whereas labour serves as the variable input. Let $c$ denote the variable input coefficient so that the aggregate production of variety $v$ in country $i$ is $X_{i}(v)=L_{X i}(v) / c$.

With respect to pricing behaviour, all firms act as monopolists setting profit maximizing prices as a fixed mark-up over marginal costs. With constant price elasticity of substitution, identical technology across firms and iceberg-type transport costs for industrial varieties, consumer prices for the domestic and the export market are given by $\widetilde{p}_{i}^{d}=c /(1-1 / \sigma)$ and $\widetilde{p}_{i}^{e}=(\tau c) /(1-1 / \sigma)$, respectively. This implies that it is optimal for all firms to charge identical producer prices $p_{i}=\widetilde{p}_{i}^{d}=\widetilde{p}_{i}^{e} / \tau$. In equilibrium, free entry of firms drives down pure profits to zero such that ${ }^{2}$

$$
\pi_{i}=\left(p_{i}-c\right) X_{i}-r_{i}=0
$$

\footnotetext{
${ }^{2}$ Although capital supply is exogenous in our model, we should nevertheless think of this as a free entry equilibrium. Firms enter the market and compete with others for scarce capital until the price for this factor breaks even with operating profits. This will occur exactly where the supplied units of capital equals the number of firms. By applying the zero-profit condition, we neglect the integer problem and treat firm numbers as continuous (see Baldwin, 1988).
} 
Setting $c=1-1 / \sigma$ normalizes producer prices to unity and $1 / \sigma$ becomes the (operating) profit margin for a unit of output sold. We thus infer from (4) that the cost of capital $\left(r_{i}\right)$ equals operating profits $\left(X_{i} / \sigma\right)$ in equilibrium.

It becomes obvious from firms' pricing behaviour that consumers have to bear trade costs entirely. Hence, demand for a domestically produced variety is lower abroad as long as $\tau>1$. This feature is central for the home market effect because firms benefit from producing in the larger market where they face higher demand for their products and thus earn higher operating profits in the absence of capital mobility.

\subsection{Labour markets}

We assume labour markets to be imperfect due to fair wage preferences of individuals. This approach has gained increasing support in the literature for good reasons. Apart from the fact that there is substantial (experimental) evidence for such preferences (Gächter and Fehr, 2002, or Bewley, 2005), the approach possesses two useful features. First, unemployment and factor price differentials can be determined endogenously in equilibrium. And, second, the fair wage parameter can easily be interpreted to measure the rigidity of relative factor prices. In other words, the fair wage mechanism introduces an elegant link between factor price compression and unemployment-a feature that is central to most other labour market rigidities (e.g. minimum wages or collective bargaining). Hence, we claim that our results should generally hold when labour market rigidity compresses relative factor prices.

The key feature of the fair wage-effort mechanism is that individuals have a preference for being remunerated in a fair way relative to a reference group. In terms of our model, workers compare their wage to operating profits of the firm they are working for. Those profits accrue solely to capital owners (who also own the firm). While standard labour market models assume that workers compare their wages to those of co-workers, recent work has stressed that firm profitability (also) serves as an important determinant for workers' expectations of fair remuneration. Danthine and Kurmann (2007) conclude after a detailed literature review that 'the better (worse) the firm is doing, the more (less) the worker expects to be paid in exchange for a given level of effort' (p.858). ${ }^{3}$

Noting that operating profits are equal to $r_{i}$ in equilibrium, the fair wage $w_{i}^{*}$ is determined in the following way:

$$
w_{i}^{*}=\beta_{i} r_{i}+\left(1-\beta_{i}\right)\left[1-u_{i}\left(1-b_{i}\right)\right] w_{i} .
$$

\footnotetext{
${ }^{3}$ See also Egger and Kreickemeier (2009) for a theoretical model with fair wages and operating profits as workers' reference.
} 
Asterisks identify the fair level, whereas $r_{i}$ and $w_{i}$ denote market prices. The fair wage equation above shows that workers attach a certain weight $\beta_{i} \in[0,1]$ to the reference income which we refer to as the fair wage parameter. The remaining weight, $1-\beta_{i}$ is put on the value of the outside option which is the expected market income for labour, where $u_{i}$ reflects the unemployment rate and $b_{i}$ is the replacement rate every individual gets if unemployed. ${ }^{4}$ While a higher unemployment rate reduces the value of the outside option, an increase in the average replacement rate renders joblessness less costly. Hence, the fair wage declines in $u_{i}$ and rises in $b_{i}$.

A further point needs highlighting. In contrast to (5), one could assume that workers use after-tax operating profits as a reference in determining their fair wage level. As we discuss below, this assumption is crucial for the direction of change in unemployment when tax rates change, but innocent for the impact of trade liberalization on Nash tax rates at a given level of labour market rigidity. Since this is the focal point of our analysis, we prefer to keep the analysis as simple as possible by abstracting from a direct tax effect on unemployment. Nevertheless, we extensively explore in Appendix 1 how our main results would be affected if net-of-tax operating profits were used in the fair-wage constraint. ${ }^{5}$

In a next step, we need to determine the wage level that maximizes firms' profits. Following Akerlof and Yellen (1990), individuals are assumed to reduce their work effort proportionally if they are remunerated less than the fair level. For workers, we have the following effort function,

$$
e_{L i}=\min \left(\frac{w_{i}}{w_{i}^{*}}, 1\right),
$$

where normal effort has been set to unity. ${ }^{6}$ According to this functional form, firms cannot influence wages per efficiency unit of labour supply. We can thus safely assume that firms choose to pay the fair wage (normalized to unity) as doing so does not reduce their profits. As an immediate consequence, workers always provide normal effort. We restrict our analysis to parameter constellations where the return to capital always exceeds the remuneration to labour to ensure that the

\footnotetext{
${ }^{4}$ To avoid further distortions, we assume that unemployment benefits are financed in a lump-sum fashion.

${ }^{5} \mathrm{~A}$ third specification could be to consider a general source-based tax on all income. Then, the labour portion of it would be neutral with labour being immobile internationally. A tax falling on both wages and profit would cancel out in (5).

${ }^{6}$ The term $e_{L i}$ is usually referred to as the effort norm in the literature. Kreickemeier and Nelson (2006) suggest to introduce a distance term $-\varepsilon_{L i}-e_{L i} \mid$ into the utility function to capture costs of deviating from the norm. As it turns out to be optimal to always supply effort $\varepsilon_{L i}$ according to the norm $e_{L i}$, the term disappears from the utility maximization problem. We have thus suppressed it from our analysis for the sake of simplicity.
} 
labour market constraint binds (with $\beta_{i}>0$ ). The equilibrium is then characterized by the following features:

$$
\begin{gathered}
u_{i}>0 \\
r_{i}>r_{i}^{*}>w_{i}=w_{i}^{*} .
\end{gathered}
$$

Inserting (7) and (8) into (5) yields the unemployment rate of workers

$$
u_{i}=\widetilde{\beta}_{i}\left(r_{i}-1\right) \text {. }
$$

where $\widetilde{\beta}_{i}=\beta_{i} /\left[\left(1-\beta_{i}\right)\left(1-b_{i}\right)\right]$. As wages have been normalized to unity, $r_{i}$ should be interpreted as the factor price differential. Since $0 \leqslant u_{i} \leqslant 1$, the return to capital is bound by $r_{i} \in\left[1 ; 1+\widetilde{\beta}_{i}^{-1}\right]$. It is evident from (9) that unemployment ceteris paribus rises in $r_{i}$.

\subsection{Governments}

We assume governments to behave benevolently by maximizing welfare. In our model, welfare in country $i$ is determined in a utilitarian way by summing over workers $L_{i}$ and capital owners $K_{i}$ as

$$
W_{i}=\left[\mu\left(\ln \mu-1-\ln P_{i}\right)+E_{i}\right]\left[L_{i}\left(1-u_{i}\right)+K_{i}\right]+\left(L_{i}+K_{i}\right) \ln \left(G_{i}\right),
$$

where $\left[\mu\left(\ln \mu-1-\ln P_{i}\right)+E_{i}\right]\left[L_{i}\left(1-u_{i}\right)+K_{i}\right]$ is aggregate indirect utility from private consumption and $G_{i}$ denotes aggregate expenditures on a public good. $G_{i}$ is financed by means of a source tax $t_{i}$ on capital income. The government budget is assumed to be balanced such that

$$
G_{i}=t_{i} r_{i} s_{n} \bar{K},
$$

where $s_{n}$ is the share of firms in country $i$ and $\bar{K}$ the global capital stock. ${ }^{7}$ Note that $G_{i}$ enters the welfare function in logarithmic form to avoid income effects. $^{8}$ When setting the tax rate, the government takes into account the relationship between a lower wage income of workers (relative to capital income) and unemployment. In contrast, individuals do not consider the impact of their behaviour and their effort reduction in response to unfair wage payments on the unemployment rate.

\footnotetext{
${ }^{7}$ In the short run, $s_{n} \bar{K}$ coincides with $K_{i}$. However, we have to use the former, more general notation as we assume that capital owners invest equally domestically and abroad. Hence, tax revenues will also be generated from domestically employed capital that is owned by foreigners.

${ }^{8}$ See Baldwin, et al., 2003, p.392. While standard assumptions exclude income effects from the model, taxation could re-introduce them because governments spend tax revenue from foreign owned capital domestically. The logarithmic treatment of $G_{i}$ in the welfare function avoids this problem.
} 


\section{Short-run effects of capital income taxation}

Before turning to the long-run allocation of firms and tax competition, we derive the equilibrium capital return with fixed capital allocation, but with potential trade in both goods. This is useful to study the implications of the fair wage constraint for relative factor prices and unemployment. First of all, we are interested in the shortrun capital return $r_{h}$. Using the insight that $r_{h}=X_{h} / \sigma$ along with optimal demand for domestic and foreign varieties yields ${ }^{9}$

$$
r_{h}=\frac{\mu}{\sigma}\left[\frac{\left(1-u_{h}\right) L_{h}+K_{h}}{K_{h}+\phi K_{f}}+\phi \frac{\left(1-u_{f}\right) L_{f}+K_{f}}{K_{f}+\phi K_{h}}\right],
$$

where $\phi \equiv \tau^{1-\sigma}$ ranges between zero and unity reflecting the freeness of trade. In particular, $\phi=0$ implies prohibitively high trade costs, whereas at $\phi=1$ trade is completely free. In order to get a first idea of how the model works, we take a look at the impact of fair wage preferences on the factor price differential and the unemployment rate. The result is summarized in Proposition $1:^{10}$

Proposition 1 A higher fair wage parameter $\beta_{h}$ reduces capital returns both domestically and abroad by causing higher unemployment in country $h$. While $u_{h}$ unambiguously increases, the reduction in demand from country $h$ for varieties produced in country $f$ can partly be offset by higher employment levels there. Raising the replacement rate $b_{h}$ exerts similar effects.

Proof See Appendix 2.

The intuition can best be demonstrated by means of (5). With a higher $\beta_{h}$, this equation can only hold if either $r_{h}$ declines or $u_{h}$ rises. However, we know from (9) that these variables are interdependent. In fact, unemployment exerts a negative impact on $r_{h}$ by reducing demand for a variety produced in country $h$. In equilibrium, demand gross of trade costs equals production $X_{h}$ which is a function of unemployment. Higher unemployment unambiguously reduces demand for each variety and thus operating profits. This effect also spills over to the other country as foreign firms face lower demand from country $h$. Applying the same reasoning for a marginal increase in $b_{h}$, it is evident from (9) that $u_{h}$ rises in $b_{h}$ implying a factor price compression effect. While a higher fair wage parameter in country $h$ unambiguously increases unemployment in country $h$, it improves employment in country $f$ (unless trade costs are prohibitively high). Intuitively, a reduction in $r_{f}$ due to a higher $\beta_{h}$ relaxes the fair wage constraint in country $f$ allowing for a lower unemployment rate.

With our specification of the fair wage constraint capital income taxes do not affect unemployment in the short run. The reason is that capital cannot be

\footnotetext{
${ }^{9}$ Note that $X_{h}=\left(L_{h}\left(1-u_{h}\right)+K_{h}\right) x_{h}+\left(L_{f}\left(1-u_{f}\right)+K_{f}\right) \tau x_{f}$. As firms are identical, we suppress the index for varieties.

${ }^{10}$ This proposition generalizes the result in Egger and Seidel (2008) to asymmetric country size.
} 
reallocated internationally rendering relative factor prices unaffected. At a given labour market rigidity as captured by the fair wage parameter, unemployment could only change, if the capital rental changed relative to wages (see (9)). Recall that these results are sensitive to the assumption whether gross or net capital returns matter for determining the fair wage level (see Appendix 1). Obviously, using after-tax capital returns implies lower unemployment when $t_{i}$ is raised.

\section{Long-run equilibrium}

We now allow capital owners to change the allocation of their capital in response to differences in after-tax capital rentals across countries. This renders the allocation of industrial firms an endogenous variable. The next subsection analyses the role of trade liberalization and imperfect labour markets for tax base responsiveness before we solve the model for both symmetric and asymmetric specifications numerically.

\subsection{Fair wages and tax base sensitivity}

To solve the model for its long-run equilibrium share of firms, $s_{n}$, we substitute $K_{h} / \bar{K}=s_{n}$ and $K_{f} / \bar{K}=1-s_{n}$ into the short-run capital return (11) and employ the location condition $\left(1-t_{h}\right) r_{h}=\left(1-t_{f}\right) r_{f}$. However, we restrict our comparative static analysis to identical countries with respect to market size $\left(L=L_{h}=L_{f}\right.$, $\left.K=K_{h}=K_{f}\right)$ and fair wage parameters $\left(\beta=\beta_{h}=\beta_{f}\right)$ for two reasons. First, it allows us to reduce the complexity of the expressions. And second, it suits better for explaining the long-run mechanism of the model. Solving the location condition for $s_{n}$ yields

$$
s_{n}=\frac{1}{2}\left(1-\frac{t_{h}-t_{f}}{2-t_{h}-t_{f}}\left(\frac{1+\phi}{1-\phi}\right)^{2}-\frac{2 \frac{\mu}{\sigma \bar{n}} \widetilde{\beta} L\left(t_{h}-t_{f}\right)}{2-t_{h}-t_{f}}\right),
$$

where $\bar{n}$ denotes the number of globally active firms. We can illustrate several points by means of (12). First, we only observe a deviation from the symmetric distribution of firms if equilibrium taxes differ between countries. Second, it is straightforward to show that an increase in any tax rate clearly reduces the share of firms in that country (unless the tax rate in the other region is unity):

$$
\frac{\partial s_{n}}{\partial t_{h}}=-\left(1-t_{f}\right) \frac{\left(\frac{1+\phi}{1-\phi}\right)^{2}+2 \frac{\mu}{\sigma \bar{n}} \tilde{\beta} L}{\left(2-t_{h}-t_{f}\right)^{2}} \leq 0 .
$$

Third, the magnitude of this effect increases in $\phi$ at exogenous tax rates,

$$
\frac{\partial^{2} s_{n}}{\partial t_{h} \partial \phi}=-\frac{1+\phi}{(1-\phi)^{3}} \frac{4\left(1-t_{f}\right)}{\left(2-t_{h}-t_{f}\right)^{2}} \leq 0 .
$$

These mechanisms are known from the literature (Baldwin, et al., 2003, p.381) and also hold true with imperfect labour markets in our model. Capital becomes more 
sensitive to tax changes if trade costs decline as it is then more attractive for firms to serve the domestic market from abroad. ${ }^{11}$

More importantly, however, we want to focus on the impact of the fair wage constraint on the equilibrium industry share $s_{n}$. Proposition 2 summarizes our findings.

Proposition 2 For countries that are identical with respect to endowments and fair wage preferences, an increase in the fair wage parameter $\beta$ reduces (increases) $s_{n}$ if $t_{h}>t_{f}\left(t_{f}>t_{h}\right)$. Similar to trade liberalization, it makes the location of capital more elastic with respect to changes in taxes.

Proof It is straightforward to show that

$$
\frac{\partial s_{n}}{\partial \beta}=-\frac{\mu}{\sigma \bar{n}} \frac{L}{(1-b)(1-\beta)^{2}} \frac{t_{h}-t_{f}}{2-t_{h}-t_{f}} \gtreqless 0
$$

and

$$
\frac{\partial^{2} s_{n}}{\partial t_{h} \partial \beta}=-\frac{2 \frac{\mu}{\sigma \bar{n}} \frac{L}{(1-b)(1-\beta)^{2}}\left(1-t_{f}\right)}{\left(2-t_{h}-t_{f}\right)^{2}} \leq 0
$$

at exogenous tax rates.

What is the intuition for this result? We know from the location condition that at $t_{h}>t_{f}$ the capital return in country $h$ must exceed the one in country $f$. Increasing fair wage preferences in both countries now generates more unemployment in country $h$ than in country $f$ as the factor price differential is higher there. Hence, a higher level of unemployment is required to meet the fair wage constraint reducing capital returns more in country $h$. As a consequence, more firms relocate from country $h$ to country $f$ than with perfect labour markets. ${ }^{12}$

In contrast to the short run, unilaterally increasing the capital income tax $t_{h}$ exhibits unemployment effects in the long run. We know that a higher tax rate in country $h$ drives firms abroad so that $r_{h}$ rises and $r_{f}$ falls. According to (9) and at given fair wage parameters, this causes more unemployment in $h$ and less unemployment in $f$.

\footnotetext{
${ }^{11}$ In fact, trade costs impede the mobility of capital in an indirect way as their level affects profits to different extents when relocating due to the home market effect. Hence, the effect of trade costs on capital flows is similar to that of costs of capital mobility. With respect to the latter, Razin and Sadka (1991) showed that higher impediments to capital mobility allow governments to set higher tax rates which enhance welfare.

${ }^{12}$ Note that in the presence of endowment differences between countries, a symmetric increase in the fair wage parameter may affect outcome even at $t_{h}=t_{f}$. We discuss the role of different country size in Appendix 3.
} 

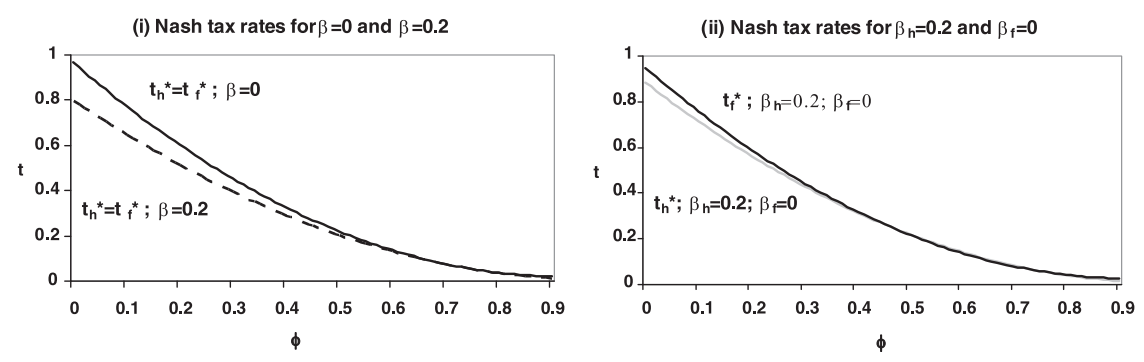

Fig. 1 Identical country size

\subsection{Tax competition}

Let us now analyse the implications of fair wage preferences for tax competition. Unfortunately, an analytical treatment of this is infeasible, but we can explore the features of the model by means of numerical analysis. Since the equilibrium allocation of capital crucially depends on trade freeness $\phi$, we need to determine equilibrium taxes and capital allocation at any level of $\phi .{ }^{13}$ We do so by implementing a grid search over $t_{h}, t_{f} \in[0,0.01, \ldots, 0.99,1]$ for each $\phi \in[0,0.01, \ldots, 0.99]$. Hence, we search for Nash equilibrium tax rates across $101^{2} \cdot 100=1,020,100$ model solutions for each level of fair wage preference parameter $\beta_{h}$ and $\beta_{f}$ so as to maximize social welfare. In particular, our focus is on the impact of $\beta_{h}$ and $\beta_{f}$ on the Nash tax rate. $^{14}$

Figure 1(i) depicts Nash tax rates for countries of identical size and equal labour market imperfection. Due to symmetry, equilibrium tax rates are identical in both countries so that it suffices to plot the curves for one jurisdiction. The solid line represents perfect labour markets as a benchmark $(\beta=0)$, whereas the dashed line shows Nash taxes for $\beta=0.2$. First, one clearly observes a race to the bottom of tax rates when $\phi$ rises. This is in line with the reported result in Section 3 that capital becomes more footloose when trade freeness goes up. Second, an increase in the fair wage parameter $\beta$ reduces Nash tax rates relative to the benchmark case while the race to the bottom in $\phi$ is preserved. The latter is not surprising since we have shown that $\beta$ increases the responsiveness of capital reallocation with respect to tax changes. Governments account for this by setting lower Nash tax rates. Notice that the impact of trade liberalization and labour market imperfections on equilibrium tax rates depend on each other. More specifically, the responsiveness of tax rates with respect to labour market imperfections declines with trade liberalization (associated with higher levels of $\phi$ in Fig. 1). As the replacement rate exerts a similar effect on unemployment, a higher level of $b$ would shift the optimal tax curve

\footnotetext{
${ }^{13}$ Although our model allows for full agglomeration of capital in principle, we exclude it from the analysis. The reason is that we would need to shift from simultaneous to sequential tax setting to establish equilibria. Obviously, this renders the results incomparable.
}

${ }^{14}$ We discuss the parameter choice for our numerical exercise in Appendix 4. 


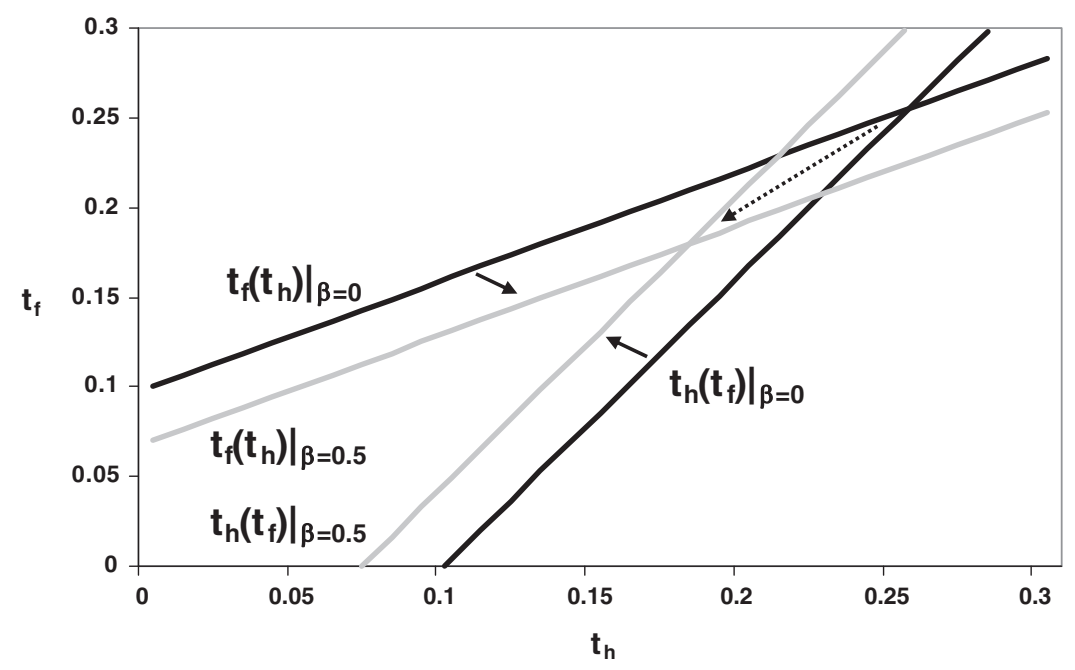

Fig. 2 Reaction functions for $\phi=0.5$

further down (as long as $\beta>0$ ). Since there are no additional insights gained, we set replacement rates to zero.

In Fig. 1(ii), we allow for differences in labour market imperfection across countries. While country $h$ is assumed to possess a fair wage parameter of $\beta_{h}=0.2$, country $f$ s labour market works perfectly. We find that the more constrained country $h$ chooses a lower Nash tax rate than country $f$. The reason is that unemployment reduces the attractiveness of this location for firms initially, so that a lower tax rate can partly offset this disadvantage. However, the tax rate is higher than with symmetrically constrained labour markets $(\beta=0.2)$ in panel (i). As unemployment in country $h$ is lower with $\beta_{h}=0.2$ and $\beta_{f}=0$ than with $\beta=0.2$, capital does not react as sensitively to tax changes. Hence, it pays off to levy higher taxes in that country. ${ }^{15}$

In the next step, we study how the labour market constraint modifies both countries' reaction curves. We choose a constellation with intermediate trade costs, $\phi=0.5$, and compare perfect labour markets, $\beta=0$, with identical fair wage constraints in both jurisdictions, $\beta>0$. For expositional reasons, we choose a sufficiently high fair wage parameter, $\beta=0.5$ for the latter case. Figure 2 illustrates that unemployment shifts reaction curves inwards. This implies that both governments set a lower Nash tax rate in equilibrium - as demonstrated in the analysis above. Since both countries levy the same capital income tax in equilibrium,

\footnotetext{
${ }^{15}$ The fact that governments choose very high capital income tax rates at high levels of trade costs is simply due to the functional form of our model. Intuitively, tax revenues from capital owners can be distributed to every citizen by providing a public good. Hence, it generates higher aggregate welfare.
} 
(i) Nash tax rates for $\beta=0$ and $\beta=0.2$

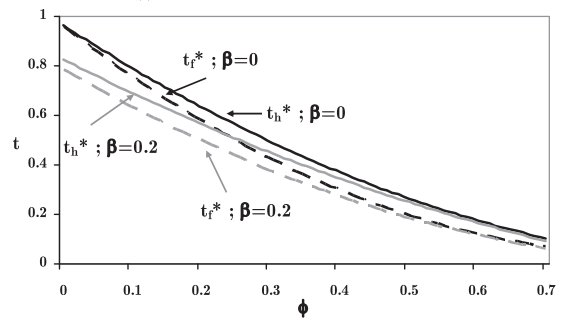

(ii) Nash tax rates for $\boldsymbol{\beta}_{\mathrm{h}}=0.2$ and $\boldsymbol{\beta}_{\mathrm{f}}=0$

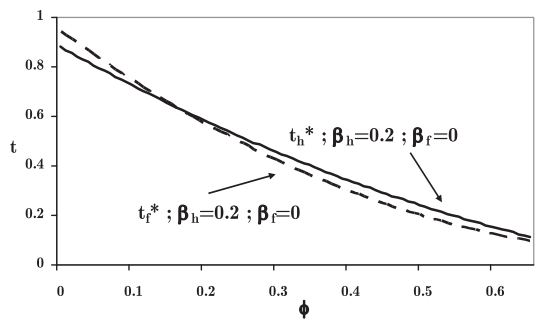

Fig. 3 Different country size

unemployment rates are also identical across countries. With a symmetric Nash equilibrium, however, unemployment rates would become different if we chose increasingly different tax rates to the right and the left of the Nash equilibrium in Fig. 2.

Finally, we assume country $h$ to be larger than country $f$ to analyse the role of market size for tax competition when labour markets are imperfect. In Fig. 3 we depict the same three fair wage scenarios as above. Figure 3(i) reports two scenarios: one in which labour markets are perfect ( $\beta=0$, displayed in black) and one in which both countries possess the same labour market constraint ( $\beta=0.2$, displayed in grey). First, one observes that the larger country $h$ (solid curves) charges a higher tax rate in equilibrium, independently of $\beta$. The tax differential reaches a maximum for intermediate levels of trade freeness because the advantage of hosting the larger market is maximal there. Second, for equally rigid labour markets Nash tax rates are still lower relative to perfect labour markets because capital reacts more sensitively to changes in tax rates, that is a marginal increase in taxes causes a higher capital outflow. However, the larger country $h$ still charges a higher tax rate than country $f$.

Panel (ii) in Fig. 3 links differences in market size to differences in fair wage preferences. Choosing a constellation in which the larger market also faces the higher labour market imperfection $\left(\beta_{h}=0.2\right.$ and $\left.\beta_{f}=0\right)$, we find that the unemployment effect dominates the market size effect for high trade barriers. Hence, Nash taxes fall short of their foreign counterpart. At some intermediate level of $\phi$, however, the advantage of possessing the larger market allows country $h$ to charge higher Nash tax rates than country $f$. Essentially, the level of trade freeness determines the relative importance of the home market advantage over the disadvantage of having the more constrained labour market for tax competition.

All simulations indicate that stronger fair wage preferences imply a lower level of welfare as tax rates have to be reduced more than with perfect labour markets. Naturally, trade liberalization (an increase in $\phi$ ) unambiguously raises welfare as less goods 'melt' on the way to consumers abroad. This leaves every household better off due to higher consumption. A last point is also obvious from our analysis, 
namely that tax harmonization allows both countries to set their welfare maximizing capital income tax rates.

\section{Conclusions}

This paper has established the novel result that imperfect labour markets increase tax base sensitivity to marginal changes in capital income taxes. In choosing the welfare maximizing tax, governments account for the negative impact of unemployment on firms' profits by setting a lower rate as this would prevent extensive relocation. The role of labour market rigidities for equilibrium tax rates on capital income depends on the degree of liberalization of international goods transactions. Stronger trade barriers render the capital tax base less responsive and, hence, capital tax rates more responsive to changes in labour market rigidities.

Finally, we point out that country size matters for government behaviour. Capital income taxes are higher in larger countries which is preserved if both economies possess the same degree of labour market imperfection. If the larger country has the more rigid labour market, however, it turns out that this imperfection depresses tax rates more for high levels of trade costs. Hence, for certain parameter values, the fair wage-constrained large country sets a lower tax rate than the unconstrained smaller country in autarky and higher tax rates with free trade.

\section{References}

Akerlof, G.A. and Yellen, J.L. (1990) The fair-wage effort hypothesis and unemployment, Quarterly Journal of Economics, 105, 255-83.

Anderson, J.E. and van Wincoop, E. (2004) Trade costs, Journal of Economic Literature, 42, 691-751.

Baldwin, R.E. (1988) Hysteresis in import prices: the beachhead effect, American Economic Review, 78, 773-85.

Baldwin, R.E., Forslid, R., Martin, P., Ottaviano, G.I.P., and Robert-Nicoud, F. (2003) Economic Geography and Public Policy, Princeton University Press, Princeton, NJ.

Baldwin, R.E. and Krugman, P. (2004) Agglomeration, integration and tax harmonization, European Economic Review, 48, 1-23.

Barros, P. and Cabral, L. (2000) Competing for foreign direct investment, Review of International Economics, 8, 360-71.

Bewley, T. (2005) Fairness, reciprocity, and wage rigidity, in H. Gintis, S. Bowles, R. Boyd, and E. Fehr (eds) Moral Sentiments and Material Interests: The Foundations of Cooperation in Economic Life, MIT Press, Cambridge, MA.

Bjorvatn, K. and Eckel, C. (2006) Policy competition for foreign direct investment between asymmetric countries, European Economic Review, 50, 1891-1907.

Borck, R. and Pflüger, M. (2006) Agglomeration and tax competition, European Economic Review, 50, 647-68.

Danthine, J.P. and Kurmann, A. (2007) The macroeconomic consequences of reciprocity in labor relations, Scandinavian Journal of Economics, 109, 857-81. 
Egger, H. and Kreickemeier, U. (2009) Fairness, trade, and inequality, mimeo, Department of Economics, University of Tübingen.

Egger, P. and Seidel, T. (2008) Agglomeration and fair wages, Canadian Journal of Economics, 41, 271-91.

Flam, H. and Helpman, E. (1987) Industrial policy under monopolistic competition, Journal of International Economics, 22, 79-102.

Fuest, C. and Huber, B. (1999) Tax coordination and unemployment, International Tax and Public Finance, 6, 7-26.

Gächter, S. and Fehr, E. (2002) Fairness in the labour market: a survey of experimental results, in F. Bolle and M. Lehmann-Waffenschmidt (eds) Surveys in Experimental Economics: Bargaining, Cooperation and Election Stock Markets, Physica Verlag, Heidelberg.

Grossman, G.M. and Helpman, E. (2008) Fair wages and foreign sourcing, in E. Helpman, D. Marin, and T. Verdier (eds) The Organization of Firms in a Global Economy, Harvard University Press, Cambridge, MA.

Haufler, A. and Mittermaier, F. (2011) Unionisation triggers tax incentives to attract foreign direct investment, Economic Journal, forthcoming.

Howitt, P. (2002) Looking inside the labor market: a review article, Journal of Economic Literature, 40, 125-38.

Kind, H.J., Midelfart Knarvik, K.H., and Schjelderup, G. (2000) Competing for capital in a 'lumpy' world, Journal of Public Economics, 78, 253-74.

Kreickemeier, U. and Nelson, D. (2006) Fair wages, unemployment and technological change in a global economy, Journal of International Economics, 70, 451-69.

Ludema, R.D. and Wooton, I. (2000) Economic geography and the fiscal effects of regional integration, Journal of International Economics, 52, 331-57.

Luttmer, E.F.P. (2005) Neighbors as negatives: relative earnings and well-being, Quarterly Journal of Economics, 120, 963-1002.

Martin, P. and Rogers, C.A. (1995) Industrial location and public infrastructure, Journal of International Economics, 39, 335-51.

Milkovich, G.T. and Newman, J.M. (2005) Compensation, McGraw Hill, New York, NY.

Ottaviano, G.I.P. and van Ypersele, T. (2005) Market size and tax competition, Journal of International Economics, 67, 25-46.

Pflüger, M. (2004) A simple, analytically solvable, Chamberlinian agglomeration model, Regional Science and Urban Economics, 34, 565-73.

Razin, A. and Sadka, E. (1991) Efficient investment incentives in the presence of capital flight, Journal of International Economics, 31, 171-81.

\section{Appendix}

\section{Using after-tax capital returns in the fair wage constraint}

Instead of using the gross capital return as the reference income for workers, one could modify the model by basing the fair wage constraint on the net capital return. 
However, this would change the tax competition results only quantitatively. The fair wage in country $i$ would then read

$$
w_{i}^{*}=\beta_{i}\left(1-t_{i}\right) r_{i}+\left(1-\beta_{i}\right)\left[1-u_{i}\left(1-b_{i}\right)\right] w_{i},
$$

and unemployment would be determined by the net capital return so that

$$
u_{i}=\widetilde{\beta}_{i}\left[r_{i}\left(1-t_{i}\right)-1\right] \text {. }
$$

As an immediate consequence of this, governments could reduce unemployment via higher tax rates in the short run. The simple reason is that the gross returns are fixed due to the fact that capital cannot be shifted abroad to avoid the tax. Hence, the outcome for unemployment is qualitatively different in the net capital returnbased model from the benchmark case.

Unemployment effects also differ between these two specification in the long-run perspective. In fact, with a net capital return-based fair wage constraint a unilateral increase in capital income taxes would-as in the short run-reduce unemployment again (while it would have increased unemployment in the paper specification). The difference to the short run, though, is that capital would be shifted abroad so that $r_{i}$ would rise. Nevertheless, the net return remains on a lower level than before the tax increase in country $i$. Hence, governments would have to increase taxes more in order to achieve the same reduction in the unemployment rate as without international capital mobility.

Despite these fundamental differences in unemployment effects, long-run Nash tax rates would only be affected quantitatively. In particular, they would be higher than with gross capital returns as the reference in the fair wage constraint. Intuitively, tax increases would not only drive capital out of the jurisdiction, but they would also reduce unemployment. As this second effect exerts a positive impact on welfare, governments would not set tax rates as low as in the absence of this effect. With positive unemployment, however, Nash tax rates would fall short of their counterpart with perfect labour markets.

\section{Proof of Proposition 1}

Defining $\kappa_{h} \equiv K_{h}+\phi K_{f}, \kappa_{f} \equiv K_{f}+\phi K_{h}$ and substituting (9) into (11) delivers

$$
r_{h}=\frac{\mu \kappa_{h}}{\sigma \kappa_{h}+\mu \widetilde{\beta}_{h} L_{h}}\left[\frac{\left(1+\widetilde{\beta}_{h}\right) L_{h}+K_{h}}{\kappa_{h}}+\phi \frac{\left(1-\widetilde{\beta}_{f}\left(r_{f}-1\right)\right) L_{f}+K_{f}}{\kappa_{f}}\right],
$$

Using the short-run capital return in country $f$ and differentiating with respect to $\beta_{h}$ yields

$$
\frac{\partial r_{h}}{\partial \beta_{h}}=\frac{\left[\sigma \kappa_{f}+\left(1-\phi^{2}\right) \mu \widetilde{\beta}_{f} L_{f}\right] \mu L_{h}}{\left(\sigma \kappa_{h}+\mu \widetilde{\beta}_{h} L_{h}\right)\left(\sigma \kappa_{f}+\mu \widetilde{\beta}_{f} L_{f}\right)-\phi^{2} \mu^{2} \widetilde{\beta}_{h} L_{h} \widetilde{\beta}_{f} L_{f}} \frac{1-r_{h}}{\left(1-b_{h}\right)\left(1-\beta_{h}\right)^{2}}<0 .
$$


The cross-border effect points to the same direction, but turns out to be smaller than the direct domestic effect:

$$
\frac{\partial r_{f}}{\partial \beta_{h}}=\frac{\phi \sigma \kappa_{f} \mu L_{h}}{\left(\sigma \kappa_{h}+\mu \widetilde{\beta}_{h} L_{h}\right)\left(\sigma \kappa_{f}+\mu \widetilde{\beta}_{f} L_{f}\right)-\phi^{2} \mu^{2} \widetilde{\beta}_{h} L_{h} \widetilde{\beta}_{f} L_{f}} \frac{1-r_{h}}{\left(1-b_{h}\right)\left(1-\beta_{h}\right)^{2}} \leq 0 .
$$

Note that $\partial r_{f} \partial \partial \beta_{h}<0$ only if trade is not restricted, that is $\phi>0$. Furthermore, since both effects are negative, we can infer that an increase in symmetric fair wage preferences across countries also reduces $r_{h}$ unambiguously.

Next, we determine the impact of fair wage preferences on the unemployment rate $u_{h}$ :

$$
\begin{aligned}
\frac{\partial u_{h}}{\partial \beta_{h}} & =\frac{r_{h}-1}{\left(1-b_{h}\right)\left(1-\beta_{h}\right)^{2}}+\widetilde{\beta}_{h} \frac{\partial r_{h}}{\partial \beta_{h}} \\
& =\frac{\sigma \kappa_{h}\left(\sigma \kappa_{f}+\mu \widetilde{\beta}_{f} L_{f}\right)}{\left(\sigma \kappa_{h}+\mu \widetilde{\beta}_{h} L_{h}\right)\left(\sigma \kappa_{f}+\mu \widetilde{\beta}_{f} L_{f}\right)-\phi^{2} \mu^{2} \widetilde{\beta}_{h} L_{h} \widetilde{\beta}_{f} L_{f}} \frac{1-r_{h}}{\left(1-b_{h}\right)\left(1-\beta_{h}\right)^{2}}>0 .
\end{aligned}
$$

For the cross-border effect we get

$$
\frac{\partial u_{f}}{\partial \beta_{h}}=\widetilde{\beta}_{f} \frac{\partial r_{f}}{\partial \beta_{h}} \leq 0 .
$$

An increase in the symmetric fair wage preference parameter $\beta$ causes direct effects (through $\partial u_{h} / \partial \beta_{h}$ ) and indirect ones (through $\partial u_{h} / \partial \beta_{f}$ ). As these effects point into opposing directions, the result is ambiguous unless both countries are of equal size. In that case, an increase in the identical fair wage parameter generates more unemployment in both countries.

The proof for comparative static results with respect to the replacement rate $b_{h}$ follows the same reasoning.

\section{Asymmetric countries}

Appendix 3 sheds some light on the interaction between fair wage parameters and tax rates when countries differ in endowments. Here, we assume that country $h$ is larger than country $f$. Figure 4 indicates that our comparative statics results for symmetric countries also show up when market size differs. For $t_{f}=0.3$ and $\phi=0.5$ we see that equally constrained labour markets reduce the share of industry in country $i$ relative to perfect labour markets $(\beta=0)$ if $t_{h}<t_{f}$ for different levels of $\beta$. The simulation exercise also confirms the finding that the tax base responsiveness to changes in the tax rate increases with higher fair wage parameters.

\section{Parametrization of the simulations for the long run}

We follow Pflüger (2004) in choosing the parameters $\mu=0.6$ and $\sigma=6$. To ensure that capital returns always exceed wages, we have to set a sufficiently high 


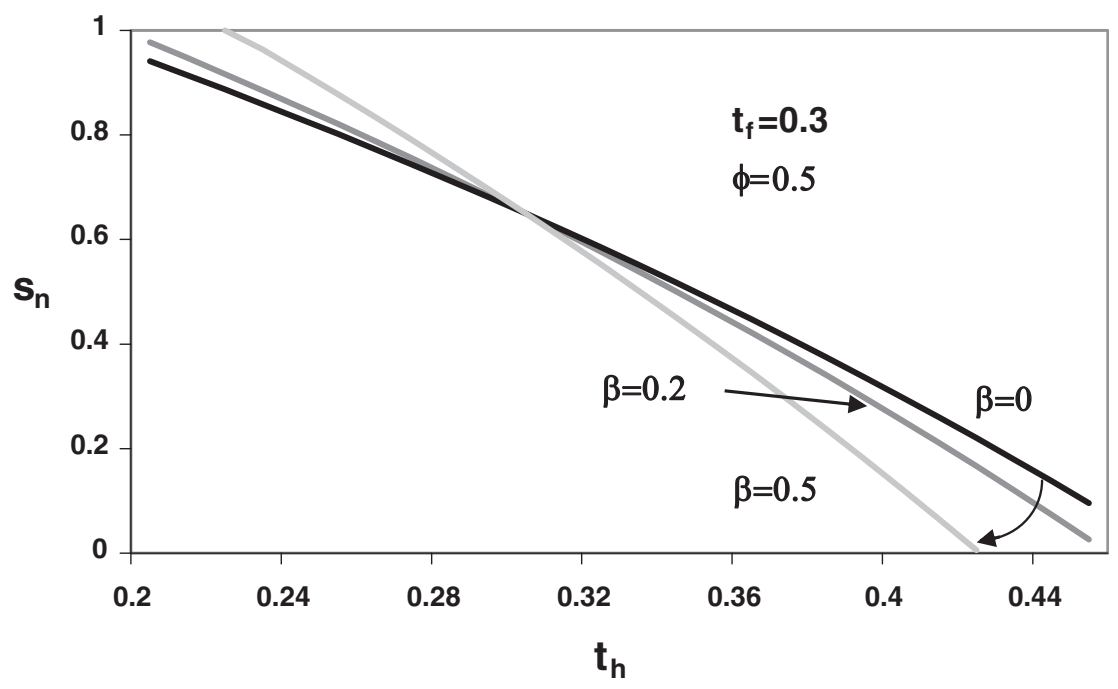

Fig. 4 Equilibrium industry share and tax rates

labour-capital ratio in each country. So, $L_{h}=L_{f}=1500$ and $K_{h}=K_{f}=100$. We compare positive fair wage parameters with $\beta=0$ to detect the impact of unemployment. We choose $\beta=0.2$ so that the change in Nash tax rates becomes visible in the diagrams. For asymmetric country size, we increased the endowment of both labour and capital of country $h$ by $10 \%$ and reduced it for country $f$ by the same percentage. 